\title{
Prognostic analysis of radiation pneumonitis: carbon-ion radiotherapy in patients with locally advanced lung cancer
}

\author{
Kazuhiko Hayashi ${ }^{1 *}$, Naoyoshi Yamamoto ${ }^{1}$, Masataka Karube², Mio Nakajima', Naruhiro Matsufuji ${ }^{3}$, Hiroshi Tsuji ${ }^{1}$, \\ Kazuhiko Ogawa ${ }^{4}$ and Tadashi Kamada ${ }^{1}$
}

\begin{abstract}
Background: Carbon-ion radiotherapy (CIRT) is a promising treatment for locally advanced non-small-cell lung cancer, especially for patients with inoperable lung cancer. Although the incidence of CIRT-induced radiation pneumonitis (RP) $\geq$ grade 2 ranges from 2.5 to 9.9\%, the association between CIRT-induced RP and dosimetric parameters is not clear. Herein, we identified prognostic factors associated with symptomatic RP after CIRT for patients with non-small-cell lung cancer.
\end{abstract}

Methods: Clinical results of 65 patients treated with CIRT between 2000 and 2015 at the National Institute of Radiological Sciences were retrospectively analyzed. Clinical stage II B disease (TNM classification) was the most common stage among the patients (45\%). The median radiation dose was 72 Gy (68-76) relative biological effectiveness (RBE) in 16 fractions. In cases involving metastatic lymph nodes, prophylactic irradiation of mediastinal lymph nodes was performed at a median dose of 49.5 Gy (RBE). The median follow-up was 22 months.

Results: Grade 2 and grade 3 RP occurred in 6 and 3 patients (9 and 5\%), respectively. No patients developed grade 4 or 5 RP. Using univariate analysis, vital capacity as a percentage of predicted (\%VC), forced expiratory volume in $1 \mathrm{~s}$ (FEV1), mean lung dose (MLD), volume of lung receiving $\geq 5 \mathrm{~Gy}(\mathrm{RBE})\left(\mathrm{V}_{5}\right), V_{10}, V_{20}$ and $V_{30}$ were determined to be the significant predictive factors for $\geq$ grade 2 RP. The receiver operating characteristic (ROC) analysis revealed the cutoff values for \%VC, FEV1, MLD, $V_{5}, V_{10}, V_{20}$ and $V_{30}$ for $\geq$ grade 2 RP, which were 86.9\%, 1. $16 \mathrm{~L}, 12.5 \mathrm{~Gy}$ (RBE), 28.8, 29.9, 20.1 and 15.0\%, respectively. In addition, the multivariate analysis revealed that \%VC $<86.9 \%$ (odds ratio $=13.7 ; p=0.0041$ ) and $V_{30} \geq 15 \%$ (odds ratio $=6.1 ; p=0.0221$ ) were significant risk factors.

Conclusions: Our study demonstrated the risk factors for $\geq$ grade 2 RP after carbon-ion radiotherapy for patients with locally advanced lung cancer.

Keywords: Radiation pneumonitis, Carbon-ion radiotherapy, Lung cancer

\section{Introduction}

Primary lung cancer is one of the most common cancers worldwide, and the most frequent type is non-small-cell lung cancer. Patients with locally advanced non-smallcell lung cancer undergo surgery, chemotherapy, and/or radiotherapy. For elderly patients or patients with serious comorbidities, radiotherapy is often the chosen

\footnotetext{
* Correspondence: hayashi.kazuhiko@qst.go.jp

${ }^{1}$ Hospital of the National Institute of Radiological Sciences, National Institutes for Quantum and Radiological Sciences and Technology, 4-9-1 Anagawa,

Inage Ward, Chiba City, Chiba Prefecture, Japan

Full list of author information is available at the end of the article
}

treatment $[1,2]$. Carbon-ion radiotherapy (CIRT) is one type of radiotherapy, and its use is spreading throughout Europe and Asia. Compared with photon radiotherapy, CIRT has the following advantages: 1) high doses can be prescribed for tumors with avoidance of the surrounding normal tissue because the dose can be locally concentrated; and 2) the relative biological effectiveness (RBE) is high, with particular efficacy for hypoxic or photonresistant tumors.

Radiation pneumonitis (RP) is a radiation-induced pulmonary injury. RP generally occurs between 1 month and 1 year after radiotherapy. For photon radiotherapy 
in lung cancer patients, the incidence of symptomatic RP has ranged from 17 to $37 \%$ [3-7], and the incidence of CIRT-induced $\mathrm{RP} \geq$ grade 2 has ranged from 2.5 to 9.9\% [8, 9]. Symptomatic RP patients sometimes require treatment with steroids or oxygenation (that is, in patients with $\geq$ grade $2 \mathrm{RP}$ ), and RP is occasionally lifethreatening. Thus, it is necessary to reduce the incidence of severe RP.

As for predictors associated with $\geq$ grade $2 \mathrm{RP}$, many studies regarding photon radiotherapy have already reported that RP risk depends on irradiated lung volume and dose. The predictive dosimetric parameters are mean lung dose (MLD), $\mathrm{V}_{13}, \mathrm{~V}_{20}, \mathrm{~V}_{30}$ and others [3-5, 10]. In addition, other clinical factors such as performance status, age, chemotherapy, tumor site and smoking history have been shown as predictive factors [11-13]. By contrast, only one study concerning CIRT for stage I lung cancer reported predictive factors for $\geq$ grade $2 \mathrm{RP}$ as follows: respiratory-gate irradiation, irradiation portals with opposing fields, and the maximum dose employed [14]. As a result, the association between dosimetric parameters and RP is not clear in terms of patients with locally advanced lung cancer who have been treated with CIRT. Thus, we analyzed the association between $\geq$ grade $2 \mathrm{RP}$ and risk factors in detail, identifying the prognostic factors using the data from patients with locally advanced non-small-cell lung cancer who underwent carbon-ion radiotherapy.

\section{Patients and methods}

\section{Patients}

This study was performed in accordance with the guidelines approved by the institutional review board of our institution. This study was a retrospective evaluation of all 141 patients who were treated with CIRT at the National Institute of Radiological Sciences (NIRS). Of these patients, 124 individuals who received CIRT between April 2000 and July 2015 were selected for the study. Eligibility criteria were as follows: 1) patients were diagnosed with non-small-cell carcinoma lung cancer by histology or cytology; 2) the clinical stage had been decided by imaging (computed tomography (CT), magnetic resonance imaging (MRI) or positron emission tomography (PET)); 3) the clinical stage ranged from II A to III $\mathrm{B}$ according to the Unio Internationalis Contra Cancrum TNM Classification $7^{\text {th }}$ edition, and the $\mathrm{N}$ stage was N0, N1 or N2 [15]; 4) the performance status was $0-2 ; 5)$ patients were not treated with chemotherapy within 4 weeks of initiation of CIRT; 6) patients were not suffering from other active cancers; 7) the estimated life expectancy was longer than 6 months; 8) patients had not received previous thoracic radiotherapy; 9) patients were not able to receive other curative therapy (surgery, chemotherapy, and/or radiotherapy) or refused it; 10) patients' CT and planning data were available for this analysis; and 11) patients received follow-up for more than 6 months at the time of the analysis. This study included 92 patients who met our criteria. Of these patients, 27 of them were excluded because they underwent a second CIRT treatment for recurrent or newly developed lesions in the lung, mediastinal lymph nodes or bone. In addition, 5 patients were excluded because their follow-up periods were less than 6 months. Of these five patients, four patients died of causes unrelated to the treatment, and one patient did not attend the follow-up appointments. Consequently, we retrospectively analyzed the clinical results and treatment plans of 65 patients with locally advanced non-small-cell lung cancer.

\section{Carbon-ion radiotherapy}

The CT images for all patients, which were fixed by an individually tailored immobilization device (Moldcare; Alcare, Tokyo, Japan; and Shelfitter; Kuraray, Osaka, Japan), were taken in the supine or the prone position, with the respiratory system. The CT images were used to develop a 3-dimensional treatment plan using inhouse HIPLAN software (NIRS, Chiba, Japan) until the end of 2011, and XiO-N (ELEKTA, Stockholm, Sweden and Mitsubishi Electric, Tokyo, Japan) was used beginning in 2012.

Carbon-ion beams were generated by the heavy ion medical accelerator in the Chiba (HIMAC) synchrotron and were delivered using the respiratory-gated irradiation system [16]. Irradiation was performed in 3-4 fields with $250 \mathrm{MeV}$ or $290 \mathrm{MeV}$ carbon ions. The most common prescribed dose was 72 Gy (RBE) in 16 fractions (45 patients, 69\%), followed by 76 Gy (RBE) in 16 fractions (11 patients, 17\%) and 68 Gy (RBE) in 16 fractions (9 patients, 14\%). All doses were administered 4 days per week over 4 weeks.

Primary lesions and metastatic lymph nodes were contoured as gross tumor volume (GTV) on the CT images. The primary lesions with a $10-\mathrm{mm}$ margin and any prophylactic lymph nodes were defined as the clinical target volume (CTV). For No cases, irradiation to prophylactic lymph nodes was omitted. Planning target volume (PTV) was defined as the CTV plus a $5-\mathrm{mm}$ safety margin to account for position uncertainty. The dose was prescribed to the isocenter. The PTV was enclosed conformally at a minimum by the $95 \%$ isodose line with the prescribed dose. If there were metastatic lymph nodes, prophylactic irradiation to mediastinal lymph nodes was performed at a median dose of 49.5 Gy (RBE). Maximum dose constraints were as follows: main bronchus, $60 \mathrm{~Gy}$ (RBE); esophagus, $50 \mathrm{~Gy}$ (RBE); and spinal cord, 30 Gy (RBE). 
Table 1 Patient characteristics

\begin{tabular}{|c|c|}
\hline Factors & Number (\%) \\
\hline \multicolumn{2}{|l|}{ Age (years) } \\
\hline median (range) & $74(46-88)$ \\
\hline \multicolumn{2}{|l|}{ Sex } \\
\hline Male & $51(78)$ \\
\hline Female & $14(22)$ \\
\hline \multicolumn{2}{|l|}{ PS } \\
\hline 0 & $22(34)$ \\
\hline 1 & $39(60)$ \\
\hline 2 & $4(6)$ \\
\hline \multicolumn{2}{|l|}{ Location of primary tumor } \\
\hline Right upper lobe & $23(35)$ \\
\hline Right middle lobe & $4(6)$ \\
\hline Right lower lobe & $17(26)$ \\
\hline Left upper lobe & $16(25)$ \\
\hline Left lower lobe & $5(8)$ \\
\hline \multicolumn{2}{|l|}{ Clinical Stage } \\
\hline$\| \mathrm{A}$ & $8(12)$ \\
\hline$\| \mathrm{B}$ & $29(45)$ \\
\hline III A & $16(25)$ \\
\hline III B & $12(18)$ \\
\hline \multicolumn{2}{|l|}{ Histology } \\
\hline Squamous cell carcinoma & $35(54)$ \\
\hline Adenocarcinoma & $26(40)$ \\
\hline Large cell carcinoma & $2(3)$ \\
\hline Non small-cell carcinoma & $2(3)$ \\
\hline \multicolumn{2}{|l|}{ Total dose } \\
\hline $68 \mathrm{~Gy}(\mathrm{RBE}) / 16 \mathrm{fr}$ & $9(14)$ \\
\hline $72 \mathrm{~Gy}(\mathrm{RBE}) / 16 \mathrm{fr}$ & $45(69)$ \\
\hline 76 Gy (RBE)/16 fr & $11(17)$ \\
\hline \multicolumn{2}{|l|}{ Chemotherapy } \\
\hline Yes & $14(22)$ \\
\hline No & $51(78)$ \\
\hline \multicolumn{2}{|l|}{ Smoking status } \\
\hline Current or previous & $56(86)$ \\
\hline Never & $9(14)$ \\
\hline \multicolumn{2}{|l|}{ Pulmonary emphysema } \\
\hline Yes & $12(18)$ \\
\hline No & $53(82)$ \\
\hline
\end{tabular}

PS performance status, RBE relative biological effectiveness, fr fractions

The dose calculation algorithm at our hospital was updated from the broad-beam calculation using in-house HIPLAN software to the pencil-beam calculation using the $\mathrm{XiO}-\mathrm{N}$ software in 2012. Different dose calculation algorithms cause different dose distributions for the same treatment. For the current study, the treatment plans calculated by the HIPLAN software were converted to DICOM format and imported into $\mathrm{XiO}-\mathrm{N}$. Their dose distributions were recalculated with $\mathrm{XiO}-\mathrm{N}$.

\section{Clinical and dosimetric analysis}

First, dosimetric parameters (PTV, MLD, $\mathrm{V}_{5}, \mathrm{~V}_{10}, \mathrm{~V}_{20}$, $\mathrm{V}_{30}, \mathrm{~V}_{40}$ and $\mathrm{V}_{50}$ ) were calculated with XiO-N using the bilateral lung volume-GTV as the all-lung volume. Second, clinical parameters (patient characteristics and pulmonary function) and dosimetric parameters associated with $\geq$ grade $2 \mathrm{RP}$ were identified using univariate analysis. Third, cutoff values of these parameters were determined using the receiver operating characteristic (ROC) curve. Finally, the predictors of $\geq$ grade $2 \mathrm{RP}$ were identified using multivariate analysis.

\section{Evaluation of radiation pneumonitis}

The severity of RP was evaluated according to The $\mathrm{Na}$ tional Cancer Institute's Common Terminology Criteria for Adverse Events version 4.0 [17]. For example, we classified the initiation of required steroids as grade 2 and oxygen induction as grade 3 .

\section{Follow-up}

After completion of treatment, follow-up observations were performed at 1, 3, 6, 9 and 12 months, and then every 3 or 6 months if serious complications did not occur. At follow-up, CT images, blood examination and respiratory function assessments were performed and, if necessary, MRI brain images and PET/CT were added.

\section{Statistical analysis}

We performed univariate analysis using Fisher's exact test or Mann-Whitney U test. Multivariate analysis was performed using the Cox proportional hazard model. Statistical significance was set at $\mathrm{p}<0.05$. The ROC curve and the Youden index were calculated to determine cutoff values. We used JMP statistical software (version 11.0) for all statistical analyses.

\section{Results}

\section{Patient characteristics}

The median follow-up period for all 65 patients was 22.0 months (6.0-145.7 months). The patients consisted of 51 males and 14 females (median age at treatment, 74 years; range, 46-88) (Table 1). Disease sites included 23 right upper lobes, 17 right lower lobes, 16 left upper lobes, 5 left lower lobes and 4 right middle lobes. The clinical stage was II A disease in 8 patients, II B disease

Table 2 Number of patients with radiation pneumonitis

\begin{tabular}{llllll}
\hline & G0 & G1 & G2 & G3 & G4 and G5 \\
\hline Number of patients & 32 & 24 & 6 & 3 & 0
\end{tabular}

G Grade 
in 29 patients, III A in 16 patients, and III B in 12 patients, according to the TNM classification system. Fourteen patients $(22 \%)$ received chemotherapy before or after CIRT. No patients received CIRT and chemotherapy concurrently. Fifty-six patients (86\%) were current or previous smokers.

\section{Incidence of radiation pneumonitis (RP)}

Table 2 shows the number of patients according to RP grade. No patients developed $\geq$ grade $4 \mathrm{RP}$. Grade $3 \mathrm{RP}$ occurred in 3 patients (5\%) at approximately 4-6 months after the initiation of CIRT. These patients were prescribed steroids and home oxygen therapy. The prescribed doses were 72 Gy (RBE) for 2 patients and 76 Gy (RBE) for 1 patient. Grade 2 RP occurred in 6 patients (9\%) at a median of 5 months (5-13 months), and all patients were treated with steroids. The prescribed doses were 76 Gy (RBE) for 1 patient, 72 Gy (RBE) for 4 patients, and $68 \mathrm{~Gy}(\mathrm{RBE})$ for 1 patient. In total, 9 patients (14\%) suffered from $\geq$ grade 2 RP.

\section{Clinical factors associated with $\geq$ grade 2 RP}

Univariate analysis results of patient characteristics with or without $\geq$ grade $2 \mathrm{RP}$ are shown in Table 3 . There were no patient characteristic factors associated with $\geq$ grade $2 \mathrm{RP}$. The incidence of $\geq$ grade $2 \mathrm{RP}$ tended to be higher for the $\geq 75$ years of age group than for patients $<75$ years of age, although the difference was not statistically significant.

Univariate analysis of the average pulmonary function was performed to explore potential prognosticators for $\geq$ grade 2 RP (Table 4). All data regarding pulmonary function were evaluated as continuous variables. The results showed that low percentage of vital capacity $(\% \mathrm{VC})$ and 1 -second forced expiratory volume (FEV1) values were significant prognostic factors for $\geq$ grade $2 \mathrm{RP}$ (\%VC: $p=$ 0.002; FEV1: $p=0.043)$. The ROC analysis was used to determine the cutoff values for \%VC (86.9\%) and FEV1 $(1.16 \mathrm{~L})$ for $\geq$ grade $2 \mathrm{RP}$. Patients were divided into two groups according to the cutoff values, and the actual incidences of $\geq$ grade 2 RP were $26.5 \%$ for $\% \mathrm{VC}<86.9 \%$ and $0 \%$ for $\% \mathrm{VC} \geq 86.9 \%(p=0.002)$. Similarly, the cutoff values were $6.8 \%$ for FEV1 $\geq 1.16$ and $28.6 \%$ for FEV1< $1.16(p=0.048)$.

\section{Dose-volume analysis of $\geq$ grade $2 \mathrm{RP}$}

The dose-volume parameters associated with $\geq$ grade 2 RP were analyzed (Table 5). The results illustrated that the mean lung dose (MLD), the volume of lung receiving $\geq 5$ Gy $(\mathrm{RBE})\left(\mathrm{V}_{5}\right), \mathrm{V}_{10}, \mathrm{~V}_{20}$ and $\mathrm{V}_{30}$ were significant predictive factors for $\geq$ grade $2 \mathrm{RP}$. The ROC analysis was used to determine the cutoff values for MLD, $V_{5}, V_{10}$, $\mathrm{V}_{20}$ and $\mathrm{V}_{30}$ for $\geq$ grade $2 \mathrm{RP}$, which were 12.5 Gy (RBE), $28.8,29.9,20.1$ and $15.0 \%$, respectively. The actual incidences of $\geq$ grade $2 \mathrm{RP}$ were $35.7 \%$ vs. $7.8 \%$ (MLD, $\geq 12.5$ Gy (RBE) vs. less than 12.5 Gy (RBE), respectively, $p=0.018), 24.1 \%$ vs. $5.6 \%\left(\mathrm{~V}_{5}, \geq 28.8 \%\right.$ vs. less than $28.8 \%$, respectively, $p=0.066), 26.1 \%$ vs. $7.1 \%\left(\mathrm{~V}_{10}\right.$, $\geq 29.9 \%$ vs. less than $29.9 \%$, respectively, $p=0.058$ ), $21.9 \%$ vs. $5.9 \%\left(\mathrm{~V}_{20}, \geq 20.1 \%\right.$ vs. less than $20.1 \%, p=$ $0.074)$, and $28.0 \%$ vs. $0 \%\left(\mathrm{~V}_{30}, \geq 15.0 \%\right.$ vs. less than $15 \%$, $p=0.022)$.

\section{Multivariate analysis of risk factors for $\geq$ grade 2 RP}

Multivariate analysis was performed for $\geq$ grade $2 \mathrm{RP}$ using the two variables with the most significant $p$ values from the univariate analysis of the clinical, pulmonary functional or dosimetric factors (Table 6). The results showed that $\% \mathrm{VC}$ (odds ratio $=13.7 ; p=0.0041$ ) and $\mathrm{V}_{30}$ (odds ratio $=6.1 ; p=0.0221$ ) were significant prognosticators for $\geq$ grade $2 \mathrm{RP}$.

\section{Discussion}

Carbon-ion radiotherapy in patients with locally advanced non-small-cell lung cancer is a promising treatment, especially for patients with inoperable lung cancer [8]. Generally, RP is a serious adverse effect of thoracic CIRT. Takahashi et al. conducted a phase I/II prospective study to investigate the safety and efficacy of CIRT in 62 patients with locally advanced non-small-cell lung cancer and reported an $8.1 \%$ incidence rate of $\geq$ grade 2 RP [8]. Our study was a retrospective study that analyzed the risk factors for $\geq$ grade $2 \mathrm{RP}$ in 65 selected patients from an initial cohort of 141 patients and showed an incidence of grade $2 / 3 \mathrm{RP}$ in 9 of 65 patients (14\%), and no patients developed grade 4/5 RP. The fact that our incidence rate was slightly higher than that of Takahashi's et al. may be attributed to a difference in eligibility criteria. Regarding photon radiotherapy in lung cancer patients, many previous studies reported rates of symptomatic RP ranging from 17 to $37 \%$ [3-7]; more current research involving photon radiotherapy alone has not reported an incidence rate of symptomatic RP. One recent study, the RTOG 0617 study concerning chemoradiotherapy, showed an $8.3 \%$ incidence rate of $\geq$ grade 2 RP. [18]. The incidence of RP from modern photon radiotherapy tended to decrease because of the accumulation of dosimetric findings and technical advances. Similarly, our results concerning CIRT-induced RP may decrease the incidence of RP in the future. We conducted this study to further improve the safety of CIRT for patients with locally advanced lung cancer.

Barriger et al. reported that symptomatic RP developed at a median of 3.5 months (0.5-12 months) after the initiation of treatment [19]. Our study showed that $\geq$ grade 2 RP occurred at a median of 5 months after the initiation of CIRT. Our result was comparable to Barriger's 
Table 3 Univariate analysis of patient characteristics

\begin{tabular}{|c|c|c|c|}
\hline Parameters & No of patients with $\geq$ G2 RP (\%) & No of patients with G0-1 RP (\%) & $p$ value \\
\hline Age & & & 0.074 \\
\hline$<75$ years old & $1(11)$ & $25(45)$ & \\
\hline$\geq 75$ & $8(89)$ & $31(55)$ & \\
\hline Sex & & & 0.392 \\
\hline Man & $6(67)$ & $45(80)$ & \\
\hline Female & $3(33)$ & $11(20)$ & \\
\hline PS & & & 0.458 \\
\hline 0 or 1 & $8(89)$ & $53(95)$ & \\
\hline 2 & $1(11)$ & $3(5)$ & \\
\hline Location of primary tumor & & & 0.706 \\
\hline Upper or Middle lobe & $7(78)$ & $36(64)$ & \\
\hline Lower lobe & $2(22)$ & $20(36)$ & \\
\hline Clinical Stage & & & 1.000 \\
\hline$\|$ & $5(56)$ & $32(57)$ & \\
\hline III & $4(44)$ & $24(43)$ & \\
\hline Total dose & & & 1.000 \\
\hline$\leq 72$ Gy RBE & $8(89)$ & $46(82)$ & \\
\hline$>72$ Gy RBE & $1(11)$ & $10(18)$ & \\
\hline Chemotherapy & & & 0.187 \\
\hline Yes & 0 & $14(25)$ & \\
\hline No & $9(100)$ & $42(75)$ & \\
\hline Brinkman Index & & & 1.000 \\
\hline$<600$ & $3(33)$ & $19(34)$ & \\
\hline$\geq 600$ & $6(67)$ & $37(66)$ & \\
\hline Pulmonary emphysema & & & 0.191 \\
\hline Yes & 0 & $12(21)$ & \\
\hline No & $9(100)$ & $44(79)$ & \\
\hline
\end{tabular}

$G$ grade, $R P$ radiation pneumonitis, $P S$ performance status, $R B E$ relative biological effectiveness

Table 4 Univariate analysis of average pulmonary function

\begin{tabular}{llll}
\hline Parameters & $\begin{array}{l}\geq \text { grade } 2 \\
\text { (min - max })\end{array}$ & $\begin{array}{l}\text { grade 0-1 } \\
\text { (min - max) }\end{array}$ & p value \\
\hline \%VC (\%) & 67.5 & 89.2 & 0.002 \\
& $(37.1-86.9)$ & $(53.2-120.8)$ & \\
FEV1 (L) & 1.17 & 1.67 & 0.043 \\
& $(0.5-1.78)$ & $(0.6-3.33)$ & \\
FEV1/FVC (\%) & 70.0 & 65.6 & 0.556 \\
& $(56.2-83.7)$ & $(34.2-99.7)$ & \\
\%DLCO (\%) & 72.6 & 78.0 & 0.644 \\
& $(32.8-123.9)$ & $(29.5-178.4)$ & \\
\hline
\end{tabular}

\%VC percent of vital capacity, FEV1 1-second forced expiratory volume, FVC forced vital capacity, \%DLCO percent of diffusing capacity for carbon monoxide result from photon radiotherapy regarding the onset of RP.

According to the reported studies of photon radiotherapy, several prognosticators such as concurrent chemotherapy, age, MLD, $\mathrm{V}_{13}, \mathrm{~V}_{20}, \mathrm{~V}_{30}$ and others were identified [3, 4, 10, 20, 21]. Multivariate analysis of our study revealed that the significant prognostic factors for $\geq$ grade $2 \mathrm{RP}$ were $\% \mathrm{VC}$ and $\mathrm{V}_{30}$. While $\mathrm{V}_{30}$ had already been identified as a prognostic factor for RP in photon therapy, in this study, \%VC prior to treatment was identified as an independent prognostic factor for RP. This may arise from the fact that our study included patients with very low pulmonary function, and they tended to advance in RP severity. In fact, the average $\% \mathrm{VC}$ of patients with $\geq$ grade $2 \mathrm{RP}$ was $67.5 \%$, and that of patients without $\geq$ grade $2 \mathrm{RP}$ was $89.2 \%$. When patients with a low \%VC suffer from RP, dyspnea often appears or the saturation percentage of oxygen in arterial 
Table 5 Univariate analysis of average dosimetric parameters

\begin{tabular}{llll}
\hline Parameters & $\begin{array}{l}\geq \text { grade 2 } \\
(\text { min }- \text { max })\end{array}$ & $\begin{array}{l}\text { grade 0-1 } \\
(\text { min - max })\end{array}$ & $p$ value \\
\hline PTV $\left(\mathrm{cm}^{3}\right)$ & 448.5 & 371.0 & 0.193 \\
& $(155.8-712.7)$ & $(73.8-1319.8)$ & \\
MLD (Gy RBE) & 12.0 & 9.0 & 0.023 \\
& $(6.5-17.0)$ & $(2.9-16.2)$ & \\
$V_{5}(\%)$ & 33.8 & 24.9 & 0.034 \\
& $(17.9-49.0)$ & $(7.0-46.1)$ & \\
$V_{10}(\%)$ & 30.6 & 22.6 & 0.045 \\
& $(15.3-46.2)$ & $(6.5-42.6)$ & \\
$V_{20}(\%)$ & 24.5 & 17.9 & 0.039 \\
& $(10.1-31.4)$ & $(5.6-36.7)$ & \\
$V_{30}(\%)$ & 19.0 & 12.9 & 0.015 \\
& $(10.1-31.4)$ & $(3.7-23.6)$ & \\
$V_{40}(\%)$ & 12.2 & 8.8 & 0.052 \\
& $(5.2-18.1)$ & $(3.1-18.9)$ & \\
$V_{50}(\%)$ & 6.7 & 5.8 & 0.442 \\
& $(2.6-13.3)$ & $(2.1-14.2)$ & \\
\hline
\end{tabular}

$P T V$ planning target volume, $M L D$ mean lung dose, $R B E$ relative biological effectiveness, $V_{X}$ volume of lung receiving $\geq X$ Gy (RBE)

blood deteriorates easily because of low vital capacity. Consequently, they need to be treated with steroids or oxygenation (that is, in patients with $\geq$ grade $2 \mathrm{RP}$ ). In the future, our findings may suggest that a dose constraint of $\mathrm{V}_{30}<15 \%$ be imposed on treatment planning, and that when patients with $\% \mathrm{VC}<86.9 \%$ are treated, special care must be provided during follow-up.

Our study had 2 limitations. First, only 9 patients developed $\geq$ grade $2 \mathrm{RP}$ because CIRT-induced RP is relatively rare [8]. Second, it was difficult to accurately distinguish RP from other types of pneumonitis because $\mathrm{RP}$ is a clinical diagnosis and can be confounded by preexisting or comorbid disease, including chronic obstructive pulmonary disease exacerbations, cardiac disease, tumor progression or infection $[19,22]$.

To further reduce the incidence of $\geq$ grade $2 \mathrm{RP}$, our results should influence treatment considerations. For example, for CIRT for lung cancer patients whose \%VC is less than $86.9 \%$, a dose constraint of $\mathrm{V}_{30}$ less than $15 \%$ should be imposed. In the future, when clinical trials of concurrent chemotherapy and CIRT are planned, these results should be informative for treatment decisions.

Table 6 Multivariate analysis of risk factors for $\geq$ grade 2 radiation pneumonitis

\begin{tabular}{llc}
\hline & \multicolumn{2}{l}{ grade 2 Radiation Pneumonitis } \\
\hline Factor & Odds Ratio $(95 \% \mathrm{Cl})$ & $p$ value \\
$\% \mathrm{VC}(<86.9 \%$ vs $\geq 86.9 \%)$ & $13.7(2.09-276.2)$ & 0.0041 \\
$V_{30}(\geq 15 \%$ vs $<15 \%)$ & $6.1(1.29-36.3)$ & 0.0221 \\
\hline$R P$ radiation pneumonitis, \%VC percent of vital capacity, RBE relative biological \\
effectiveness, $V_{30}$ volume of lung receiving $\geq 30$ Gy RBE
\end{tabular}

\section{Conclusions}

Our study identified $\% \mathrm{VC}<86.9 \%$ (odds ratio $=13.7$ ) and $\mathrm{V}_{30} \geq 15 \%$ (odds ratio $=6.1$ ) as significant risk factors for $\geq$ grade 2 RP. Our study was a single institutional retrospective analysis, and further multi-institutional prospective studies are warranted.

\section{Abbreviations}

\%DLCO: Percent of diffusing capacity for carbon monoxide; \%VC: Percent of vital capacity; CIRT: Carbon-ion radiotherapy; CT: Computed tomography; CTV: Clinical target volume; FEV1: 1-second forced expiratory volume; fr: Fractions; FVC: Forced vital capacity; G: Grade; GTV: Gross tumor volume; HIMAC: The Heavy lon Medical Accelerator in Chiba; MLD: Mean lung dose; MRI: Magnetic resonance imaging; NIRS: National Institute of Radiological Sciences; PET: Positron emission tomography; PS: Performance status; PTV: Planning target volume; RBE: Relative biological effectiveness; ROC: Receiver operating characteristic; RP: Radiation pneumonitis; $V X$ : Volume of lung receiving $\geq X$ Gy (RBE)

\section{Acknowledgements}

We are grateful to the Working Group for Lung Cancer at the NIRS and the dosimetrists from the Accelerator Engineering Corporation.

Funding

Not applicable

Availability of data and materials

Not applicable

\section{Authors' contributions}

NY, HT and TK designed the study. KH and MK collected and analyzed the data, and $\mathrm{KH}$ performed the statistical analyses. $\mathrm{KH}$ and NY drafted the manuscript. All authors revised the manuscript and approved the final version.

\section{Competing interests}

The authors declare that they have no competing interests.

\section{Consent for publication}

Not applicable

\section{Ethics approval and consent to participate}

We obtained written informed consent from patients and approval from the institutional review boards of our institutions for this retrospective study.

\section{Publisher's Note}

Springer Nature remains neutral with regard to jurisdictional claims in published maps and institutional affiliations.

\section{Author details}

${ }^{1}$ Hospital of the National Institute of Radiological Sciences, National Institutes for Quantum and Radiological Sciences and Technology, 4-9-1 Anagawa, Inage Ward, Chiba City, Chiba Prefecture, Japan. ${ }^{2}$ Department of Radiotherapy, Mitsui Memorial Hospital, Tokyo, Japan. ${ }^{3}$ Department of Accelerator and Medical Physics, Research Center for Particle Therapy, National Institute of Radiological Sciences, Chiba, Japan. ${ }^{4}$ Department of Radiation Oncology, Osaka University Graduate School of Medicine, Osaka, Japan.

Received: 24 March 2017 Accepted: 24 May 2017

Published online: 30 May 2017

\section{References}

1. Hayakawa K, Mitsuhashi N, Katano S, Saito Y, Nakayama Y, Sakurai H, et al. High-dose radiation therapy for elderly patients with inoperable or unresectable non-small cell lung cancer. Lung Cancer. 2001;32:81-8.

2. Reinfuss M, Glinski B, Kowalska T, Kulpa J, Zawila K, Reinfuss K, et al. Radiotherapy for stage III, inoperable, asymptomatic small cell lung cancer. 
Final results of a prospective randomized study (240 patients). Cancer Radiother. 1999;3:475-9.

3. Graham MV, Purdy JA, Emami B, Harms W, Bosch W, Lockett MA, et al. Clinical dose-volume histogram analysis for pneumonitis after 3D treatment for non-small cell lung cancer (NSCLC). Int J Radiat Oncol. 1999;45:323-9.

4. Hernando ML, Marks LB, Bentel GC, Zhou SM, Hollis D, Das SK, et al. Radiation-induced pulmonary toxicity: a dose-volume histogram analysis in 201 patients with lung cancer. Int J Radiat Oncol Biol Phys. 2001;51:650-9.

5. Kwa SL, Lebesque JV, Theuws JC, Marks LB, Munley MT, Bentel G, et al. Radiation pneumonitis as a function of mean lung dose: an analysis of pooled data of 540 patients. Int J Radiat Oncol Biol Phys. 1998;42:1-9.

6. Oetzel D, Schraube P, Hensley F, Sroka-Pérez G, Menke M, Flentje M. Estimation of pneumonitis risk in three-dimensional treatment planning using dosevolume histogram analysis. Int J Radiat Oncol Biol Phys. 1995;33:455-60.

7. Sunyach MP, Falchero L, Pommier P, Perol M, Arpin D, Vincent M, et al. Prospective evaluation of early lung toxicity following three-dimensional conformal radiation therapy in non-small-cell lung cancer: preliminary results. Int J Radiat Oncol Biol Phys. 2000;48:459-63.

8. Takahashi W, Nakajima M, Yamamoto N, Yamashita H, Nakagawa K, Miyamoto T, et al. A prospective nonrandomized phase I/ll study of carbon ion radiotherapy in a favorable subset of locally advanced non-small cell lung cancer (NSCLC). Cancer. 2015;121:1321-7.

9. Miyamoto T, Baba M, Sugane T, Nakajima M, Yashiro T, Kagei K, et al. Carbon ion radiotherapy for stage I non-small cell lung cancer using a regimen of four fractions during 1 week. J Thorac Oncol. 2007;2:916-26.

10. Kong F-M, Hayman JA, Griffith KA, Kalemkerian GP, Arenberg D, Lyons S, et al. Final toxicity results of a radiation-dose escalation study in patients with non-small-cell lung cancer (NSCLC): predictors for radiation pneumonitis and fibrosis. Int J Radiat Oncol Biol Phys. 2006;65:1075-86.

11. Quon H, Shepherd FA, Payne DG, Coy P, Murray N, Feld R, et al. The influence of age on the delivery, tolerance, and efficacy of thoracic irradiation in the combined modality treatment of limited stage small cell lung cancer. Int J Radiat Oncol Biol Phys. 1999;43:39-45.

12. Robnett TJ, Machtay M, Vines EF, McKenna MG, Algazy KM, McKenna WG Factors predicting severe radiation pneumonitis in patients receiving definitive chemoradiation for lung cancer. Int J Radiat Oncol Biol Phys. 2000;48:89-94.

13. Yamada M, Kudoh S, Hirata K, Nakajima T, Yoshikawa J. Risk factors of pneumonitis following chemoradiotherapy for lung cancer. Eur J Cancer. 1998;34:71-5.

14. Miyamoto T, Yamamoto N, Nishimura H, Koto M, Tsujii H, Mizoe J, et al. Carbon ion radiotherapy for stage I non-small cell lung cancer. Radiother Oncol. 2003;66:127-40.

15. Sobin $L H$, Gospodarowicz MK, Wittekind C, editors. International union against cancer. TNM classification of malignant tumours. 7th ed. New York: Wiley-Blackwell Inc; 2009.

16. Minohara S, Kanai T, Endo M, Noda K, Kanazawa M. Respiratory gated irradiation system for heavy-ion radiotherapy. Int J Radiat Oncol Biol Phys. 2000;47:1097-103.

17. Services UDOHAH. Common Terminology Criteria for Adverse Events v4.0. NIH publication. 2009. https://evs.ncinih.gov/ftp1/CTCAE/CTCAE_4.03_2010-06-14_ QuickReference_5x7.pdf.

18. Bradley JD, Paulus R, Komaki R, Masters G, Blumenschein G, Schild S, et al. Standard-dose versus high-dose conformal radiotherapy with concurrent and consolidation carboplatin plus paclitaxel with or without cetuximab for patients with stage IIIA or IIIB non-small-cell lung cancer (RTOG 0617): a randomised, two-by-two factorial phase 3 study. Lancet Oncol. 2015;16:187-99.

19. Barriger RB, Forquer JA, Brabham JG, Andolino DL, Shapiro RH, Henderson MA, et al. A dose-volume analysis of radiation pneumonitis in non-small cell lung cancer patients treated with stereotactic body radiation therapy. Int J Radiat Oncol Biol Phys. 2012;82:457-62.

20. Byhardt RW, Scott C, Sause WT, Emami B, Komaki R, Fisher B, et al. Response, toxicity, failure patterns, and survival in five Radiation Therapy Oncology Group (RTOG) trials of sequential and/or concurrent chemotherapy and radiotherapy for locally advanced non-small-cell carcinoma of the lung. Int J Radiat Oncol Biol Phys. 1998;42:469-78.

21. Claude L, Pérol D, Ginestet C, Falchero L, Arpin D, Vincent M, et al. A prospective study on radiation pneumonitis following conformal radiation therapy in non-small-cell lung cancer: clinical and dosimetric factors analysis. Radiother Oncol. 2004;71:175-81.

22. Kocak Z, Evans ES, Zhou S-M, Miller KL, Folz RJ, Shafman TD, et al. Challenges in defining radiation pneumonitis in patients with lung cancer. Int J Radiat Oncol Biol Phys. 2005;62:635-8.

\section{Submit your next manuscript to BioMed Central and we will help you at every step:}

- We accept pre-submission inquiries

- Our selector tool helps you to find the most relevant journal

- We provide round the clock customer support

- Convenient online submission

- Thorough peer review

- Inclusion in PubMed and all major indexing services

- Maximum visibility for your research

Submit your manuscript at www.biomedcentral.com/submit
Biomed Central 